\title{
Making Decisions about Self-Disclosure in Online Social Networks
}

\author{
Alireza Heravi \\ University of South Australia \\ alireza.heravi@mymail.unisa.edu.au \\ Kim-Kwang Raymond Choo \\ University of Texas at San Antonio \\ University of South Australia \\ raymond.choo@fulbrightmail.org
}

\author{
Deepa Mani \\ University of South Australia \\ deepa.mani@mymail.unisa.edu.au \\ Sameera Mubarak \\ University of South Australia \\ sameera.mubarak@unisa.edu.au
}

\begin{abstract}
This paper explores privacy calculus decision making processes for online social networks (OSN). Content analysis method is applied to analyze data obtained from face-to-face interviews and online survey with open-ended questions of 96 OSN users from different countries. The factors users considered before self-disclosing are explored. The perceived benefits and risks of using OSN and their impact on self-disclosure are also identified. We determine that the perceived risks of OSN usage hinder selfdisclosure. It is not clear, however, whether the perceived benefits offset the impact of the risks on selfdisclosure behavior. The findings as a whole do not support privacy calculus in OSN settings.
\end{abstract}

\section{Introduction}

Decision making can be regarded as choosing the best option among alternatives and the judgment in the selection is based "on knowledge in memory or from analyzing benefits, costs, and risk" [1] (p. 19).

In the privacy literature, several studies have attempted to conceptualize how individuals make privacy related decisions and maintain a balance between privacy and self-disclosure (any information about the self that a person reveals to others). Through the lens of communication privacy management theory [2], self-disclosure and privacy are dialectical in nature, and in order to regulate the tensions between the two and reach a decision, people develop and enact rules. These rules guide people on whether to reveal or conceal private information, and are based on five criteria, namely: culture, gender, motives, context, and risk-benefit ratio [3]. The dilemma is referred to as privacy calculus when the risk-benefit ratio or cost- benefit analysis is the basis for making a decision about self-disclosure.

The concept of privacy calculus was commonly used to explain consumers' decision to, or not to, disclose personal information to businesses [4, 5]. In recent years, this approach has been explored in a number of online social networks (OSN) studies (see Appendix). The research on privacy calculus in OSN, perhaps best represented by [6], is mostly limited to quantitative studies that separately examine the effects of the perceived benefits and anticipated risks on the research topic. Most of these studies do not examine the decision process or the trade-offs made between the benefits and risks involved in privacy calculus, which is the focus of this study.

Mintzberg, Raisinghani and Théorêt [7] argue that while the processes used in individual decision making are not predetermined and explicit, "a basic logic or structure underlies what the decision maker does" ( $p$. 274). To explore the logic of decision making, we need to understand and identify the themes and patterns of its processes. Understanding, themes and patterns are elements of qualitative research findings [8]. In qualitative research, the attempt is to interpret the research topic in terms of the meanings people attach to them [9].

Therefore, it seems that qualitative research is more appropriate than quantitative research to gain an indepth understanding of the cognitive process in making a decision on whether or not to provide personal information on OSN. Moreover, in most quantitative research on OSN privacy calculus, the constructs of the benefits and risks are based on literature review and contain a fixed number of items. This limits the scope of the constructs; therefore, the cognitive process of decision making is not fully explored. In contrast, in qualitative research, the sub-categories of the benefits and costs of self-disclosure can be developed from the qualitative data and literally there is no limit to the number of sub-categories. Therefore, a complete range 
of the categories (limited to the qualitative data) can be obtained. Few studies, however, have employed qualitative research to investigate privacy calculus in OSN.

In addition to the low number of the qualitative research on OSN privacy calculus, these studies use student samples (i.e. [10-12]) which limit the generalization of their findings. Moreover, most research is conducted based on the assumption that privacy calculus behaviors occur in OSN.

Therefore, to contribute to the body of knowledge, we sample both students and the general OSN users and conduct a qualitative research (i.e. interviews and survey with open-ended questions) and use content analysis method to examine whether or not OSN users engage in privacy calculus. More importantly, we seek to capture and understand the dynamics of the privacy calculus process. The ultimate aim of the current study is to address the following research question: Is privacy calculus the basis for making decisions about self-disclose on OSN? To answer this question, the following questions are explored:

- RQ1-What are the perceived benefits and risks of using OSN?,

- RQ2-What factors do users consider before providing personal information on OSN? and

- RQ3-What is the impact of the perceived benefits/risks of OSN usage on self-disclosure and time spent on OSN?

\section{Literature review}

\subsection{Privacy calculus}

The term calculus, as a basis for decision making on disclosure or non-disclosure of personal information, was introduced by Laufer and Wolfe [13] as the "calculus of behavior". The authors argued that regarding information disclosure management, individuals have "to decide the probable future consequences of [their] current [disclosure] behavior" (p. 36). They, however, emphasized that due to unpredictability of the changes in society and technologies, individuals are "often unable to predict the nature of that which has to be managed" (p. 37).

In addition to interpersonal relationships, Culnan and Armstrong [4] claimed that the notion of calculus is evident in customer-business relationships as well. The authors used the term "privacy calculus" and defined it as the willingness of individuals to "disclose personal information in exchange for some economic or social benefit subject to ...[the] assessment that their personal information will subsequently be used fairly and they will not suffer negative consequences" [4] (p.
106). They argued that the customers will continue to disclose personal information that is required for transactions as long as the perceived benefits exceed the risks. The findings in [14] suggested that customers are willing to sacrifice a certain portion of their privacy for gaining some financial or convenience benefits.

\subsection{Privacy calculus in OSN}

We conducted a systematic search for scholarly articles on Google Scholar and other academic databases (e.g. Web of Science and ScienceDirect) using keywords such as "privacy calculus" and "perceived benefits/risks" in combination with terms such as "online social network", "Facebook", and "social network site". The focus of the review was limited to articles that (1) explicitly and empirically investigated OSN using privacy calculus framework, and (2) published in a peer-reviewed journal or conference proceedings (e.g. HICSS). Therefore, conceptual studies such as [15] were not included in our literature review. The literature search was completed in February 2016. We located 19 published articles.

Privacy calculus has been applied to explore a variety of topics in OSN settings. The theme of most of the studies, however, is to investigate self-disclosure behavior on OSN. The complete list of the articles is presented in Appendix.

Quantitative research has been used in most of the articles [16-28]. An example of such study is [26], which showed that both relationship management and usefulness of Facebook (benefits) have positive effects, and privacy concerns (risks) have a negative impact on users' intentions to disclose personal information on Facebook. The authors found that only the combined effects of the benefits can offset the risks of selfdisclosure. In another study [24], researchers reported that the benefits of using Facebook (i.e. convenience of maintaining existing relationships, building new relationships, enjoyment, and self-presentation) were significant factors that predicted self-disclosure on the platform. The perceived privacy risk, however, did not exert any significant negative influence on users' selfdisclosure.

Qualitative research was employed in a small number of studies [10-12] to explore privacy calculus in OSN. The authors in [10] conducted interviews and used Grounded Theory method to investigate privacy calculus in German teenage $(n=9)$ Facebook users. They found that the teenagers weigh the benefits (self-presentation, keeping in touch with friends, peer support, and entertainment) against the costs (waste of time, social conflict, information overload, expose to $\mathrm{x}$-rated content, information accessibility to a wide 
variety of persons) when they disclose personal information on Facebook. The study in [12] uses the privacy calculus paradigm and conducts focus groups to explore the perception of alcohol consumption in related posts on Facebook and their implications for peer socialization among college students. The author claims that students' evaluation about the benefits and risks of their disclosure regarding alcohol consumption is not accurate. This is due to the fact that the discloser of the inappropriate post does not receive any comments from their peers and, therefore, cannot evaluate the risk of their disclosure.

Another study [6] employed both research methods to explore self-disclosure on OSN. Based on their qualitative (i.e. two focus groups; 16 students) findings, the authors tested their proposed selfdisclosure model and found that the perceived benefits (i.e. convenience of maintaining and developing relationships and platform enjoyment) were positive and the perceived privacy risk was negative when related to users' self-disclosure on OSN.

\section{Research methodology}

Our qualitative research included both face-to-face interview and online survey with open-ended questions. The online survey was employed to reduce bias in the face-to-face interviews as this method enables participants to express themselves without embarrassment [29]. Erickson and Kaplan [30] posited that open-ended surveys offer greater anonymity and elicit more novel, unanticipated and honest responses. It is suggested that the use of the two methods increases the validity of the findings [29].

To avoid arbitrary interpretation of self-disclosure across participants, we defined self-disclosure to our participants as any personal information users provide on their profile (name, photo, contact details, political and religious affiliation, work/education information, etc.), and in the communication process with other users (e.g. wall posts, status updating, commenting and private messaging).

\subsection{In-depth interviews}

As some participants are more likely to provide more insight than others, random sampling for interviews is not considered to be appropriate [31]. In qualitative research, the basis of sample selection is the characteristics of the samples rather than the chances of being selected [32]. It was expected that by interviewing only experienced and active OSN users, we would achieve the breadth of coverage across privacy calculus in OSN. Therefore, two selection criteria for interviewees were placed, namely: being a member of an OSN for at least two years; and using OSN on a daily basis for at least 30 minutes. Using a snowball method, we invited 23 students who met the selection criteria to interview. Participation in interview was voluntary. Interview participants comprised 11 males (48\%) and 12 females (52\%), with a mean age of 34.7 ( $\mathrm{SD}=8.2$, range $=21-53$ years old). Interviewees came from 9 countries, with 7 $(30.4 \%)$ from India, 5 (15.6\%) from Malaysia, and 3 (13\%) from Australia. On average, they had 404.2 OSN friends and daily spent 75 minutes on OSN.

Following the guidelines described in [33], we conducted the interviews between November and December 2015 at the University of South Australia. Each interview lasted 20 minutes on average and was audio recorded with the participant's permission and later transcribed. Interview participants were also informed that their responses would be aggregated in a dataset and no personal identifiable information would be saved.

\subsection{Online survey with open-ended questions}

Respondents were recruited from SurveyMonkey and were compensated for their effort. It is suggested that the web-based survey solutions can be used to obtain cost effective and time-saving high-quality data [34]. Moreover, SurveyMonkey provides the opportunity to have a more diverse sample frame of the general public OSN users. In SurveyMonkey, researchers can target respondents based on specific attributes to obtain responses from the people whose opinions they need. In order to maintain consistency between the interview data and survey data, we set the attributes the same as the selection criteria for the interviewees.

To reduce common method bias, we followed the recommendations outlined in [35]. Respondents were assured that there is no right or wrong answer and were encouraged to answer questions as honestly as possible. More importantly, anonymity was ensured to diminish the probability of participants feeling pressure to answer the questions in a way they think is expected.

Moreover, as suggested in [36], a trap question (i.e. respondents were asked to select a specific scale) was deigned to screen out inattentive respondents who were not cognitively engaged during answering the survey questions. We received 123 responses from SurveyMonkey. After removing the responses that failed to accurately answer the trap question or having incomplete responses, 73 usable responses remained. From the 73 survey respondents, $36(49.3 \%)$ were male and $37(50.7 \%)$ female. The mean age was 44.4 (SD= 16.6 , range $=18-69$ years old), and on average they had 
346.6 OSN friends and daily spent 127.6 minutes on OSN. The majority of the survey respondents were from the US $(n=62,85 \%)$.

\subsection{Data analysis}

Since the selection criteria for participants and the asked questions were similar in both methods, the interview data (i.e. interview transcripts) and survey data were aggregated into one dataset. The respondents' answers to the survey questions and the interview transcripts resulted in a document of 24,651 words that served as the basis for our analysis.

Following the guidelines of [37], content analysis was used to analyze the document. Content analysis is a flexible method for analyzing text data [38] and is defined as "a research method for the subjective interpretation of the content of text data through the systematic classification process of coding and identifying themes or patterns" [39] (p. 1278). Textual information can be obtained using a variety of methods including interviews, and open-ended survey questions [40]. In content analysis, both the content and context of the text data are analyzed. In identifying themes, the focus is on how the theme is treated or presented as well as the frequency of its occurrence [41].

Two independent coders were involved in the coding process. We systematically checked the accuracy of the coding. First, when one third of the dataset was independently coded by each of the coders (i.e. assigning the units of analysis to the identified categories of the coding scheme), the reliability of the coding process was assessed using Cohen's kappa. The value of inter-coder reliability ranges from 0 (or $0 \%$ ) to 1 (or $100 \%$ ). Values closer to one represent higher reliability or agreement between the coders. The minimum recommended level for Cohen's kappa is 0.7 [37]. As the reliability of some of the categories was low (kappa <0.7), the coding rules were revised. Next, both coders applied the revised rules to the same coded categories. Then, kappa was accessed. This time, the acceptable level of reliability was achieved (kappa $>0.7$ ). Finally, inter-coder reliability for all the identified categories was examined when the entire data was coded. The kappa level for the categories ranged between 0.75 and 1.00 , suggesting a high level of agreement between the coders. Cohen's kappa was calculated using IBM SPSS Statistics v21.

\section{Findings and discussion}

To answer RQ1, the perceived benefit and risk of using OSN was considered the unit of analysis, and the categories and coding scheme were inductively developed from our dataset. As most participants stated more than one benefit/risk for OSN use, the total number of the benefits $(n=206)$ and risks $(n=272)$ is more than the total number of the participants $(n=96$, 23 interviewees and 73 survey respondents). Nine codebook sub-categories for the benefits (see Table 1) and fourteen codebook sub-categories for the risks (see Table 2) were identified.

Table 1. Perceived benefits of using OSN

\begin{tabular}{|l|l|}
\hline Category & Category definition \\
\hline $\begin{array}{l}\text { Maintaining } \\
\text { relationships } \\
91(44.4 \%)\end{array}$ & $\begin{array}{l}\text { Keep in contact with } \\
\text { acquaintances, friends and } \\
\text { families. }\end{array}$ \\
\hline $\begin{array}{l}\text { Information } \\
\text { seeking } \\
38(18.5 \%)\end{array}$ & $\begin{array}{l}\text { Get information (e.g. community } \\
\text { events, educational purposes, what } \\
\text { people are up to) }\end{array}$ \\
\hline $\begin{array}{l}\text { Photos } \\
23(11.2 \%)\end{array}$ & Seeing/sharing photos \\
\hline $\begin{array}{l}\text { News } \\
17(8.3 \%)\end{array}$ & $\begin{array}{l}\text { Using OSN to get news (e.g. } \\
\text { politics, sports, current affairs) }\end{array}$ \\
\hline $\begin{array}{l}\text { New } \\
\text { relationships } \\
15(7.3 \%)\end{array}$ & $\begin{array}{l}\text { Using OSN for the opportunity to } \\
\text { make new personal and/or } \\
\text { business relationships. }\end{array}$ \\
\hline $\begin{array}{l}\text { Game } \\
7(3.4 \%)\end{array}$ & Using OSN for plying games. \\
\hline $\begin{array}{l}\text { Pass time } \\
5(2.4 \%)\end{array}$ & $\begin{array}{l}\text { Using OSN to pass time when } \\
\text { bored and/ or waiting. }\end{array}$ \\
\hline $\begin{array}{l}\text { Fun } \\
5(2.4 \%)\end{array}$ & Using OSN for enjoyment \\
\hline $\begin{array}{l}\text { Content } \\
\text { sharing } \\
5(2.4 \%)\end{array}$ & $\begin{array}{l}\text { Sharing content on OSN (e.g. } \\
\text { articles, videos, links) }\end{array}$ \\
\hline
\end{tabular}

The numbers refer to the frequency and the relative importance of each category.

It was observed that the perceived benefits and motivation for using OSN were similar among research participants. As argued in [42], the relationship between the benefits and motives for using OSN can be explained through the lens of the Uses and Gratification theory. The salient expected benefit of OSN use was found to be Maintaining relationships. This is consistent with the findings in [43]. The review of the literature in [42] found that the most common identified benefits/motives for OSN use are relationship maintenance, entertainment, relationship building, and information seeking.

The participants who were not concerned about privacy due to their safe practice of OSN tend to be satisfied with the idea of having control through OSN privacy settings. A typical comment was: "I don't have a problem with the privacy, because they provide ways to keep most unwanted ones out". 
To address RQ2, the unit of analysis was defined as the factor users consider before providing personal information on OSN. The categories were derived directly from the worded document. As some participants reported considering more than one factor, the total number of the factors $(n=154)$ is more than the total number of the participants $(\mathrm{n}=96)$. Table 4 lists the ten identified factors.

Table 2. Perceived risks of using OSN

\begin{tabular}{|l|l|}
\hline Category & Category definition \\
\hline $\begin{array}{l}\text { Privacy breach } \\
46(16.9 \%)\end{array}$ & $\begin{array}{l}\text { Accessing personal information } \\
\text { without the OSN user's consent }\end{array}$ \\
\hline $\begin{array}{l}\text { Not concerned } \\
29(10.7 \%)\end{array}$ & $\begin{array}{l}\text { Being not concerned about the } \\
\text { risks of using OSN due to safe } \\
\text { OSN practice }\end{array}$ \\
\hline $\begin{array}{l}\text { Hackers } \\
20(7.4 \%)\end{array}$ & OSN profiles get hacked \\
\hline $\begin{array}{l}\text { Stalkers } \\
20(7.4 \%)\end{array}$ & Being stalked on OSN \\
\hline $\begin{array}{l}\text { Scams } \\
18(6.6 \%)\end{array}$ & Being victimized by OSN scams \\
\hline $\begin{array}{l}\text { Waste of time } \\
17(6.3 \%)\end{array}$ & Excessive time spent on OSN \\
\hline $\begin{array}{l}\text { Identity theft } \\
17(6.3 \%)\end{array}$ & $\begin{array}{l}\text { Being impersonated by using } \\
\text { the personal details that have } \\
\text { been obtained from OSN } \\
\text { profiles. }\end{array}$ \\
\hline $\begin{array}{l}\text { Adverse impact } \\
17(6.3 \%)\end{array}$ & $\begin{array}{l}\text { Negative effect of commenting, } \\
\text { sharing contents (e.g. friends } \\
\text { getting offended, being hurt by } \\
\text { peoples' comments) }\end{array}$ \\
\hline $\begin{array}{l}\text { Addiction } \\
16(5.9 \%)\end{array}$ & Getting addicted to using OSN \\
\hline $\begin{array}{l}\text { Misuse of } \\
\text { information } \\
16(5.9 \%)\end{array}$ & $\begin{array}{l}\text { Information provided on OSN } \\
\text { be misused by individuals, } \\
\text { government agencies or } \\
\text { companies }\end{array}$ \\
\hline $\begin{array}{l}\text { Inappropriate } \\
\text { content } \\
16(5.9 \%)\end{array}$ & $\begin{array}{l}\text { Being exposed to inappropriate } \\
\text { content (e.g. extreme views, } \\
\text { depictions of } \\
\text { nudity/pornography) }\end{array}$ \\
\hline $\begin{array}{l}\text { Lack of real } \\
\text { privacy control } \\
15(5.5 \%)\end{array}$ & $\begin{array}{l}\text { Incapability of fully protecting } \\
\text { personal information on OSN }\end{array}$ \\
\hline $\begin{array}{l}\text { Spams } \\
13(4.8 \%)\end{array}$ & $\begin{array}{l}\text { Receiving irrelevant or } \\
\text { unsolicited messages over OSN }\end{array}$ \\
\hline $\begin{array}{l}\text { Retention of } \\
\text { information } \\
12(4.4 \%)\end{array}$ & $\begin{array}{l}\text { Information will remain on the } \\
\text { internet for ever }\end{array}$ \\
\hline the frequency
\end{tabular}

The numbers refer to the frequency and the relative importance of each category.

As listed in Table 3, only 3 (3.1\%) participants did not take into account any consideration when providing information. Of these participants, two of them believed that using OSN is not risky and the third participant, a female aged 67, stated "I'm too old to have privacy".

Generally, the identified factors were consistent with previous findings. For example, in [44], it was shown that sensitivity of the information and its appropriateness and the information's audience are important factors in influencing information disclosure on OSN. Findings relating to the Consequence factor echoed those discussed in [45]. The study [45] reported that when making privacy decisions about online photo sharing, individuals consider the potential risks associated with location information and whereabouts. Similarly, Cautiousness factor was regarded in [46] as self-censorship that some Facebook users adopted.

Table 3. Factors considered before providing personal information

\begin{tabular}{|c|c|}
\hline Category & Category definition \\
\hline $\begin{array}{l}\text { Cautiousness } \\
38(24.7 \%)\end{array}$ & $\begin{array}{l}\text { Disclosing no or very limited } \\
\text { personal information }\end{array}$ \\
\hline $\begin{array}{l}\text { Privacy } \\
25(16.2 \%)\end{array}$ & $\begin{array}{l}\text { Disclosing information only to } \\
\text { the desired audience }\end{array}$ \\
\hline $\begin{array}{l}\text { Accessibility } \\
24(15.6 \%)\end{array}$ & $\begin{array}{l}\text { Who will have access to the } \\
\text { information? }\end{array}$ \\
\hline $\begin{array}{l}\text { Consequence } \\
22(14.3 \%)\end{array}$ & $\begin{array}{l}\text { What are the negative } \\
\text { consequences of providing the } \\
\text { information? (e.g. possibility of } \\
\text { identity theft, being stalked } \\
\text { etc...) }\end{array}$ \\
\hline $\begin{array}{l}\text { Impact } \\
11(7.1 \%)\end{array}$ & $\begin{array}{l}\text { How the information would } \\
\text { affect others (e.g. hurting } \\
\text { someone's feelings, damage to } \\
\text { self-reputation) }\end{array}$ \\
\hline $\begin{array}{l}\text { Information } \\
\text { content } \\
9(4.8 \%) \\
\end{array}$ & $\begin{array}{l}\text { What the information contains } \\
\text { (e.g. is it sensitive?) }\end{array}$ \\
\hline $\begin{array}{l}\text { Public } \\
9(4.8 \%)\end{array}$ & $\begin{array}{l}\text { Whether I mind if the } \\
\text { information is known to } \\
\text { everyone }\end{array}$ \\
\hline $\begin{array}{l}\text { Appropriateness } \\
7(4.5 \%)\end{array}$ & $\begin{array}{l}\text { Whether the information is } \\
\text { fascinating or appropriate for } \\
\text { those who receive it }\end{array}$ \\
\hline $\begin{array}{l}\text { Identifiability } \\
6(3.9 \%)\end{array}$ & $\begin{array}{l}\text { Whether the information can be } \\
\text { used to identify the sender }\end{array}$ \\
\hline $\begin{array}{l}\text { None } \\
3(1.9 \%)\end{array}$ & Considering no factor \\
\hline
\end{tabular}

To address RQ3, we explored whether perceived benefits (perceived risks) of using OSN would encourage (discourage) users to share more personal information and/or spend more time on OSN. The 
results of our analysis are presented in Table 4 and Table 5.

\section{Table 4. The impact of the perceived benefits}

OSN benefits, the encouraging factor to spent more time and share more personal information

\begin{tabular}{|c|c|c|c|}
\hline \multicolumn{2}{|c|}{ Time } & \multicolumn{2}{c|}{ Information } \\
\hline Yes & No & Yes & No \\
\hline $35(36.5 \%)$ & $61(63.5 \%)$ & $19(19.8 \%)$ & $78(81.3 \%)$ \\
\hline
\end{tabular}

Table 5. The impact of the perceived risks

OSN risks, the discouraging factor to spent more time and share more personal information

\begin{tabular}{|c|c|c|c|}
\hline \multicolumn{2}{|c|}{ Time } & \multicolumn{2}{c|}{ Information } \\
\hline Yes & No & Yes & No \\
\hline $40(41.7 \%)$ & $56(58.3 \%)$ & $46(47.9 \%)$ & $50(52.1 \%)$ \\
\hline
\end{tabular}

The results suggest that majority of the participants believed neither the benefits nor the risks of using OSN affect their self-disclosure and time spent on OSN. Some participants, however, pointed out that the benefits encourage them to provide more general information rather than personal information (e.g. date of birth or intimate details). An interviewee said "I find Facebook very useful for keeping in touch with family and friends or to find out what's going on and get the news. I enjoy using Facebook. It might cause me to spend more time, yes but share more personal info, no way. Maybe I share more general info, but not any personal info". Similarly, a survey participant stated "I only write more about my passions not anything personal". We determined that perceived benefits motivate participants to use OSN rather than encouraging them to disclose personal information.

Most of the participants who were of the view that the risks do not discourage them from self-disclosing indicated that they do not provide much personal information and therefore are not at risk. An interviewee said "I am not discouraged. I am just careful about what I even respond to. I think Facebook is dangerous. That is why you can only find very little about me on Facebook". One survey participant's comment was typical: "I don't spend much time or share much about myself, so the risks don't affect me". This attitude towards privacy may be explained by the findings of [42], which argue the third-person effect causes users to be less wary of privacy.

Generally, participants did not believe in sacrificing information privacy to gain any benefit from using OSN. Most of them adopted a conservative approach (i.e. not providing personal information that is sensitive). Only one participant (out of 96) admitted to some extent accepting the negative balance of the risks in favor of the benefits. She said "I think a loss of privacy is the price we pay for being connected".

It was evident that in participants' decision making about self-disclosure, the risks had a far greater impact than the benefits. The total number of the perceived risks $(n=272)$ was more than the total number of the perceived benefits $(n=206)$; indicating participants made more comments on risks. Moreover, from the 14 identified factors that users consider before making a privacy decision, no benefit factor was determined. In fact, the benefits did not play an important role in the decision process.

Privacy calculus is referred to as the "decision process" [5] (p.62), which consists of the trade-off between perceived benefits and risks of information disclosure. In the privacy calculus paradigm, selfdisclosure of an OSN user is based on the user's subjective calculation and analysis of the risks and benefits. If the benefits outweigh the risks, then it is more likely that the user will proceed with disclosing information on OSN. In other words, if both benefits and risks are not weighted against each other when making a decision, then privacy calculus would not take place because no trade-off has occurred and as McKnight, Lankton, and Tripp pointed out, "the decision [would be] too simple to be called a calculus" [18] (P. 1). The findings in [47, 48] suggest that individuals may be incapable of considering both dimensions (i.e. benefits and risks) in the privacy calculus equation. Dong, Jin, and Knijnenburg in [44] took the discussion to the next level by postulating that users' privacy decision-making on OSN is far from being calculated or even rational.

The findings of this study as a whole do not support privacy calculus because participants did not take into account the benefit factors. This is in line with the findings in [18], which suggested OSN users' benefits perceptions (i.e. usefulness of Facebook and enjoyment) did not shape their self-disclosure intentions. In [26], it was also suggested that relationship management and perceived usefulness of OSN (benefits) did not offset users' perceived privacy concerns (risks) about using OSN.

Reliance on self-reported data rather than actual behavior is a limitation of this study. Based on our findings, OSN users appear to be generally cautious in providing information and make disclosure decisions based on multiple factors. Future research will include empirically uncovering privacy decision making processes by examining users' actual privacy behavior.

\section{Conclusion}

This research is one of few studies to address the cognitive process of privacy calculus in OSN context. 
We postulated that qualitative research is the appropriate approach for exploring the topic and this research used the content analysis method to analyze our qualitative data.

To explore the privacy decisions process, three steps were taken. First, the perceived benefits (i.e. Maintaining relationships, Information seeking, Photos, News, Establishing new relationships, Games, Pass time, Fun and Content sharing) and anticipated risks (i.e. Privacy breach, Hackers, Stalkers, Scams, Waste of time, Identity theft, Adverse impact, Addiction, Misuse of information, Inappropriate content, Lack of real privacy control, Spams and Retention of information) of using OSN were identified. Next, the factors users consider before selfdisclosing were determined. The nine factors in order are: Cautiousness, Privacy, Accessibility, Consequence, Impact, Information content, Public, Appropriateness, and Identifiability.

Finally, the impact of the perceived benefits and risks on self-disclosure and time spent on OSN was examined. The perceived benefits and risks did not affect the majority of the participants in terms of the degree of their self-disclosure and the time they spent on OSN. Generally, participants were cautious in information disclosure and engaged in an evaluation process when deciding to self-disclose on OSN. Most users considered possible negative consequences before revealing personal information. The perceived risks of OSN usage indeed hinder self-disclosure. It was not clear, however, whether the perceived benefits offset the impact of the risks on self-disclosure behavior. It seems that the perceived benefits motivate people to use OSN, but not necessarily encouraged them to reveal more about themselves.

Overall, the results suggest that privacy calculus or the trade-off between the expected benefits and risks were not supported.

\section{References}

[1] T. L. Saaty, "How to Make a Decision: The Analytic Hierarchy Process," Interfaces, vol. 24, pp. 19-43, 1994.

[2] S. Petronio and I Alt an, Boundaries of Privacy: Dialectics of Disclosure. Albany, NY: State University of New York Press, 2002.

[3] E. A. Griffin, A first look at communication theory, 7th ed. Boston: McGraw-Hill Higher Education, 2009.

[4] M. J. Culnan and P. K. Armstrong, "Information Privacy Concerns, Procedural Fairness, and Impersonal Trust: An Empirical Investigation," Organization Science, vol. 10, pp. 104-115, 1999.
[5] T. Diev and P. Hart, "An Extended Privacy Calculus Model for E-Commerce Transactions," Information Systems Research, vol. 17, pp. 61-80, 2006.

[6] H. Krasnova, S. Spiekermann, K. Koroleva, and T. Hildebrand, "Online social networks: why we disclose," Journal of Information Technology, vol. 25, pp. 109-125, 2010 .

[7] H. Mintzberg, D. Raisinghani, and A. Théorêt, "The Structure of 'Unstructured' Decision Processes," Administrative Science Quarterly, vol. 21, pp. 246-275, 1976.

[8] M. Q. Patton, Qualitative research and evaluation methods, 3rd ed. Thousand Oaks, Sage Publications, 2002.

[9] N. K. Denzin and Y. S. Lincoln, Collecting and interpreting qualitative materials. Thousand Oaks, Sage Publications, 1998.

[10] K. Koroleva, F. Brecht, L. Goebel, and M. Malinova, "'Generation Facebook'-A Cognitive Calculus Model of Teenage User Behavior on Social Network Sites", in AMCIS 2011 proceedings, Detroit, Michigan.

[11] N. Eling, H. Krasnova, T. Widjaja, and P. Buxmann, "Will you accept an app? empirical investigation of the decisional calculus behind the adoption of applications on Facebook", in 34th International Conference on Information Systems, Milan, 2013.

[12] L. Wolfer, "They shouldn't post that! Student perception of inappropriate posts on Facebook regarding alcohol consumption and the implications for peer socialization," Journal of Social Sciences, vol. 10, pp. 77-85, 2014.

[13] R. S. Laufer and M. Wolfe, "Privacy as a Concept and a Social Issue: A Multidimensional Developmental Theory," Journal of Social Issues, vol. 33, pp. 22-42, 1977.

[14] I.-H. Hann, K.-L. Hui, S.-Y. T. Lee, and I. P. L. Png, "Overcoming Online Information Privacy Concerns: An Information-Processing Theory Approach," Journal of Management Information Systems, vol. 24, pp. 13-42, 2007.

[15] M. Tschersich and R. Botha, "Exploring the impact of restrictive default privacy settings on the privacy calculus on social network sites," in 22ed European Conference on Information Systems, Tel Aviv, 2014.

[16] H. Krasnova and F. Veltri, "Privacy Calculus on Social Networking Sites: Explorative Evidence from Germany and USA", in 43rd Hawaii International Conference on System Sciences, 2010.

[17] H. Krasnova and N. F. Veltri, "Behind the curtains of privacy calculus on social networking sites: the study of Germany and the USA," in 10th international conference on Wirtschaftsinformatik, Zurich, Switzerland, 2011, pp. 891900. 
[18] D. H. McKnight, N. Lankton, and J. Tripp, "Social Networking Information Disclosure and Continuance Intention: A Disconnect", in 44th Hawaii International Conference on System Sciences, 2011.

[19] N. F. Veltri, H. Krasnova, and W. Elgarah, "Online Disclosure and Privacy Concerns: a Study of Moroccan and American Facebook Users," in AMCIS, Detroit, Michigan, 2011.

[20] H. Krasnova, N. F. Veltri, and O. Günther, "Selfdisclosure and privacy calculus on social networking sites: The role of culture," Business \& Information Systems Engineering, vol. 4, pp. 127-135, 2012.

[21] F. Xu, K. Michael, and X. Chen, "Factors affecting privacy disclosure on social network sites: an integrated model," Electronic Commerce Research, vol. 13, pp. 151168, 2013.

[22] I. Catoiu, M. Orzan, O.-I. Macovei, and C. Iconaru, "Modelling Users' Trust in Online Social Networks," Amfiteatru Economic, vol. 16, pp. 289-302, 2014.

[23] D. Wilson, J. Proudfoot, and J. Valacich, "Saving face on Facebook: privacy concerns, social benefits, and impression management", in 35th International Conference on Information Systems, Auckland, 2014.

[24] C. Christy, W. Y. L. Zach, and K. H. C. Tommy, "Selfdisclosure in social networking sites: The role of perceived cost, perceived benefits and social influence," Internet Research, vol. 25, pp. 279-299, 2015.

[25] T. L. James, M. Warkentin, and S. E. Collignon, "A dual privacy decision model for online social networks," Information \& Management, vol. 52, pp. 893-908, 2015.

[26] J. Min and B. Kim, "How are people enticed to disclose personal information despite privacy concerns in social network sites? The calculus between benefit and cost," Journal of the Association for Information Science and Technology, vol. 66, pp. 839-857, 2015.

[27] J. Shibchurn and X. Yan, "Information disclosure on social networking sites: An intrinsic-extrinsic motivation perspective," Computers in Human Behavior, vol. 44, pp. 103-117, 2015.

[28] Y. Sun, N. Wang, X.-L. Shen, and J. X. Zhang, "Location information disclosure in location-based social network services: Privacy calculus, benefit structure, and gender differences," Computers in Human Behavior, vol. 52, pp. 278-292, 2015.

[29] J. W. Creswell, Research design : qualitative, quantitative, and mixed methods approaches, 2nd ed. Thousand Oaks, Sage Publications, 2003.
[30] P. I. Erickson and C. P. Kaplan, "Maximizing Qualitative Responses about Smoking in Structured Interviews," Qualitative Health Research, vol. 10, pp. 829840, 2000.

[31] M. N. Marshall, "Sampling for qualitative research," Family Practice, vol. 13, pp. 522-526, 1996.

[32] J. Ritchie, J. Lewis, and E. Gillian, "Designing and Selecting Samples," in Qualitative research practice: A guide for social science students and researchers, J. Ritchie and J. Lewis, Eds., Sage, 2003, pp. 77-104.

[33] R. Legard, J. Keegan, and K. Ward, "In-depth Interviews," in Qualitative research practice: A guide for social science students and researchers, J. Ritchie and J. Lewis, Eds., Sage, 2003, pp. 138-169.

[34] E. Symonds, "A practical application of SurveyMonkey as a remote usability-testing tool," Library Hi Tech, vol. 29, pp. 436-445, 2011.

[35] P. M. Podsakoff, S. B. MacKenzie, L. Jeong-Yeon, and N. P. Podsakoff, "Common Method Biases in Behavioral Research: A Critical Review of the Literature and Recommended Remedies," Journal of Applied Psychology, vol. 88, p. 879, 2003.

[36] D. M. Oppenheimer, T. Meyvis, and N. Davidenko, "Instructional manipulation checks: Detecting satisficing to increase statistical power," Journal of Experimental Social Psychology, vol. 45, pp. 867-872, 2009.

[37] B. Downe-Wamboldt, "Content analysis: Method, applications, and issues," Health Care for Women International, vol. 13, pp. 313-321, 1992.

[38] S. Cavanagh, "Content analysis: concepts, methods and applications," Nurse researcher, vol. 4, pp. 5-13, 1997.

[39] H.-F. Hsieh and S. E. Shannon, "Three Approaches to Qualitative Content Analysis," Qualitative Health Research, vol. 15, pp. 1277-1288, 2005.

[40] N. L. Kondracki, N. S. Wellman, and D. R. Amundson, "Content Analysis: Review of Methods and Their Applications in Nutrition Education," Journal of Nutrition Education and Behavior, vol. 34, pp. 224-230, 2002.

[41] L. Spencer, J. Ritchie, and W. O'Connor, "Analysis: Practices, Principles and Processes," in Qualitative research practice: A guide for social science students and researchers, J. Ritchie and J. Lewis, Eds., Sage, 2003, pp. 200-209

[42] A. Heravi, S. Mubarak, and K.-K. R. Choo, "Online Social Networking Has a Greater Effect on Others than on Me: A Third-Person Effect Perspective", in 26th Australasian Conference on Information Systems, Adelaide, Australia, 2015. 
[43] P. Sheldon, "The relationship between unwillingness-tocommunicate and students' Facebook use," Journal of Media Psychology, vol. 20, pp. 67-75, 2008.

[44] C. Dong, H. Jin, and B. P. Knijnenburg, "Predicting Privacy Behavior on Online Social Networks," in Ninth International AAAI Conference on Web and Social Media (ICWSM), Oxford, UK, 2015.

[45] S. Ahern, D. Eckles, N. S. Good, S. King, M. Naaman, and R. Nair, "Over-exposed?: privacy patterns and considerations in online and mobile photo sharing".

Proceedings of the SIGCHI Conference on Human Factors in Computing Systems, San Jose, California, USA, 2007.

[46] Y. Wang, G. Norcie, S. Komanduri, A. Acquisti, P. G. Leon, and L. F. Cranor, "I regretted the minute I pressed share: A qualitative study of regrets on Facebook," in Proceedings of the Seventh Symposium on Usable Privacy and Security, 2011, p. 10.
[47] T. Dinev, H. Xu, J. H. Smith, and P. Hart, "Information privacy and correlates: an empirical attempt to bridge and distinguish privacy-related concepts," European Journal of Information Systems, vol. 22, pp. 295-316, 2013.

[48] F. Kehr, D. Wentzel, and P. Mayer, "Rethinking the privacy calculus: on the role of dispositional factors and affect", in 34th International Conference on Information Systems, Milan, Italy, 2013.

[49] M. Tschersich and M. Niekamp, "Pros and Cons of Privacy by Default: Investigating the Impact on Users and Providers of Social Network Sites", in 48th Hawaii International Conference on System Sciences 2015, pp. 1750-1756.

\section{Appendix}

\begin{tabular}{lll}
\multicolumn{2}{l}{ Different topics and the examined perceive risks and perceived benefits in OSN privacy calculus studies } \\
\hline Study & Topic & Costs/Benefits \\
\hline & $\begin{array}{l}\text { What motivates OSN users to disclose } \\
\text { Personal information }\end{array}$ & $\begin{array}{l}\text { Cost: Privacy risk } \\
\text { Benefit: Convenience of maintaining relationships, Relationship } \\
\text { building, Self-presentation, Enjoyment }\end{array}$ \\
\hline
\end{tabular}

[16] How cultural differences impact selfdisclosure in Facebook

What motivates and hinders teenagers to
use Facebook and how using this medium
affects their identities?
[17] Cultural differences between German and
American participants of OSNs.

[18] OSN users' information disclosure and their usage continuance intention.

[19] Cultural differences between Moroccan and American participants of OSNs.

201 Cultural differences between German and American participants of OSNs.

Decisional calculus behind the adoption
of applications on Facebook.

[21] Factors affecting users' self-disclosure of personal information on renren.com
Cost: Privacy concern, Perceived damage of privacy violations, Perceived likelihood of various privacy violations

Benefit: Enjoyment, Self-presentation, Relationship maintenance

Cost: Waste of time, Social conflict, Information overload, Expose to $X$-rated content, Information accessibility to a wide variety of persons

Benefit: Self-presentation, Keeping in touch with friends, Peer support, Entertainment, Expect communication, Exchange personal or school related information, Desire to initiate a connection online, and Arrange offline meetings

Cost: Privacy risk

Benefit: Enjoyment, Trust in OSN provider

Cost: Privacy concern, Information sensitivity

Benefit: Trusting beliefs, Perceived usefulness Enjoyment

Cost: Privacy concern, Perceived damage of privacy violations, Perceived likelihood of various privacy violations

Benefit: Enjoyment, Self-presentation, Relationship maintenance

Cost: Privacy concern

Benefit: Enjoyment

Cost: Data access by the app, Data usage, Loss of control over posting, Data linkage across networks, and Fraud

Benefit: Perceived usefulness (app performance), interest, fun

Cost: Information privacy concern

Benefit: Perceived benefits 


\begin{tabular}{|c|c|c|}
\hline [22] & Trust in OSN & $\begin{array}{l}\text { Benefit: Perceived benefits } \\
\text { Cost: Perceived concerns and Perceived risks }\end{array}$ \\
\hline \multirow[t]{2}{*}[15]{} & \multirow{2}{*}{$\begin{array}{l}\text { The impact of restrictive default privacy } \\
\text { settings on the privacy calculus on } \\
\text { Facebook. }\end{array}$} & $\begin{array}{l}\text { Cost: Privacy concern, Perceived damage of privacy violations, } \\
\text { Perceived likelihood of various privacy violations }\end{array}$ \\
\hline & & Benefit: Enjoyment, Self-presentation, Relationship maintenance \\
\hline \multirow{2}{*}{ [23] } & \multirow{2}{*}{$\begin{array}{l}\text { How privacy concerns can be } \\
\text { counterbalanced by the perceived social } \\
\text { benefits to support impression } \\
\text { management. }\end{array}$} & $\begin{array}{l}\text { Cost: Privacy concerns (general information privacy concerns, } \\
\text { site-specific privacy concerns) }\end{array}$ \\
\hline & & Benefit: Perceived social benefits \\
\hline \multirow{2}{*}[12]{} & \multirow{2}{*}{$\begin{array}{l}\text { Perception of alcohol consumption related } \\
\text { posts on Facebook and its implications } \\
\text { for peer socialization. }\end{array}$} & $\begin{array}{l}\text { Cost: Admitting underage drinking to family and (possibly) } \\
\text { employers }\end{array}$ \\
\hline & & $\begin{array}{l}\text { Benefit: show participating in college partying culture and Peer } \\
\text { acceptance }\end{array}$ \\
\hline \multirow[b]{2}{*}{ [24] } & \multirow{2}{*}{$\begin{array}{l}\text { The impacts of perceived } \\
\text { cost/benefits/social influence on self- } \\
\text { disclosure in Facebook. }\end{array}$} & Cost: Perceived privacy risk \\
\hline & & $\begin{array}{l}\text { Benefit: Convenience of maintaining existing relationships, New } \\
\text { relationship building, Self-presentation, and Enjoyment }\end{array}$ \\
\hline$[25]$ & $\begin{array}{l}\text { Information privacy management (dual } \\
\text { privacy decision) in Facebook. }\end{array}$ & $\begin{array}{l}\text { Cost: Privacy of Information and Interaction management } \\
\text { Benefit: Seek information, Socialization, Self-Expression, } \\
\text { Pleasing others }\end{array}$ \\
\hline [26] & $\begin{array}{l}\text { Why People disclose personal } \\
\text { information despite privacy concerns on } \\
\text { Facebook? }\end{array}$ & $\begin{array}{l}\text { Cost: Privacy concerns } \\
\text { Benefit: Relationship management, Self-presentation }\end{array}$ \\
\hline \multirow[b]{2}{*}{ [27] } & \multirow{2}{*}{$\begin{array}{l}\text { Examining information disclosure } \\
\text { intentions through intrinsic-extrinsic } \\
\text { perspective }\end{array}$} & Cost: Perceived risks \\
\hline & & Benefit: Perceived usefulness \\
\hline \multirow{2}{*}{ [28] } & \multirow{2}{*}{$\begin{array}{l}\text { Location information disclosure behavior } \\
\text { in location-based social network services. }\end{array}$} & Cost: Privacy risks \\
\hline & & Benefit: Utilitarian benefits and hedonic benefits \\
\hline \multirow[t]{2}{*}{ [49] } & \multirow{2}{*}{$\begin{array}{l}\text { The impact of restrictive default privacy } \\
\text { settings on the privacy calculus on } \\
\text { Facebook. }\end{array}$} & $\begin{array}{l}\text { Cost: Privacy concern, Perceived damage of privacy violations, } \\
\text { Perceived likelihood of various privacy violations }\end{array}$ \\
\hline & & Benefit: Enjoyment, Self-presentation, Relationship maintenance \\
\hline
\end{tabular}

